\title{
Lei geral da copa, álcool e o processo de criação da legislação sobre violência
}

Heloisa Helena Baldy dos Reis*

\begin{abstract}
Resumo: Este artigo trata da Lei Geral da Copa que tramita no Congresso Nacional desde setembro de 2011, sob a sigla de PL 2330/2011 de autoria do Poder Executivo. Nesse é feita uma análise sobre a Lei Geral da Copa e o processo de construção da legislação sobre violência e prevenção desta em espetáculos esportivos, mais detidamente sobre a polêmica vinculação entre álcool e violência.
\end{abstract}

Palavras-chave: Legislação; violência, Copa do Mundo.

\section{INTRODUÇÃo}

Este artigo trata da Lei Geral da Copa que tramita no Congresso Nacional desde setembro de 2011, sob a sigla de PL 2.330/2011 de autoria do Poder Executivo. Segundo os signatários ${ }^{1}$ da carta endereçada a presidenta, o texto refere-se ao "Projeto de Lei Geral que dispõe sobre medidas relativas à Copa das Confederações FIFA 2013 e à Copa do Mundo FIFA2014, que serão realizadas no Brasil. Tais medidas se fazem necessárias para a efetivação dos compromissos assumidos pelo Governo Federal perante a FIFA, quando da escolha do país como sede das Competições." (BRASIL, 2011a, p. 13).

A proposição legislativa (PL 2.330/2011) pretende então, tratar (BRASIL, 2011a, p. 13-14):

\footnotetext{
"Departamento de Ciências do Esporte. Faculdade de Educação Física. Unicamp. Campinas, SP, Brasil. E-mail: helobaldy@yahoo.com

'Orlando Silva de Jesus Junior, Antonio de Aguiar Patriota, Paulo Roberto dos Santos Pinto, José Eduardo Martins Cardozo, Guido Mantega, Fernando Damata Pimentel, Paulo Bernardo Silva, Anna Maria Buarque de Hollanda, Luis Inacio Lucena Adams e Miriam Aparecida Belchior.
} 
Das definições "acerca de entidades, pessoas, locais, objetos" entre outros, definições estas similares às já utilizadas na Lei no. 12.350/2010 que dispõe sobre as medidas tributárias para a realização dos eventos supramencionados.

i. Da Proteção e Exploração de Direitos Comerciais.

ii. Visto de entrada e das permissões de trabalho.

iii. Da Responsabilidade Civil, a qual define a responsabilidade do Governo Federal perante terceiros.

iv. Dispõe sobre a venda de ingressos.

v. Disposições Finais que permite a criação de Juizados, Varas e Câmaras Especializadas para julgamentos relativas às competições.

Exposto os motivos da propositura legislativa, é necessário dizer que este artigo faz uma análise sobre a Lei Geral da Copa e o processo de construção da legislação sobre violência e prevenção desta em espetáculos esportivos, mais detidamente sobre a polêmica vinculação entre álcool e violência.

\section{Aspectos METOdOLóGicos}

Em termos de metodologia, a pesquisa da qual este artigo é fruto é uma pesquisa longitudinal desenvolvida desde 1999 que procura conhecer, entender e descrever o processo de construção de uma política brasileira de prevenção da violência em espetáculos esportivos, particularmente o futebolístico e a elaboração de legislação e normas que contribuam para a concretude desta. Os procedimentos metodológicos são: revisão de literatura nos campos do Direito esportivo e da Sociologia, a observação, análise de documentos (projetos de leis, leis, decretos) no âmbito federal, estadual e municipal; análise de matérias jornalísticas em jornais e na internet.

A revisão da literatura é um procedimento contínuo e de longo prazo que a investigadora realiza desde 1999 sobre o tema, tanto no Brasil como na Europa, tendo como referência as produções em língua inglesa e castelhana. 
A observação como procedimento metodológico da pesquisa refere-se a inserção de longo prazo da pesquisadora no debate regional e nacional sobre a violência relacionada aos espetáculos esportivos e a sua prevenção, assim como uma analista das proposituras legislativas sobre futebol e violência no Brasil. As observações são realizadas nos intensos debates com os operadores do direito, políticos e jornalistas, momentos em que interesses velados são explicitados muitas vezes sem nenhum pudor.

A análise dos documentos busca referencias históricos de leis, normas, projetos de leis sobre a temática deste artigo e permite as interpretações objetivas e subjetivas dos textos legais e o interesse do legislador.

\section{MegaeVentos}

A falta de consenso quanto ao conceito ou significado do termo megaeventos já foi abordada por Tavares (2011) que constatou

[...] uma ausência quase absoluta de conceituação do termo "megaevento" na produção nacional. Não é de fato surpreendente que textos não acadêmicos façam uso do termo sem evidenciar maiores necessidades de definição e esclarecimento sobre o que é um megaevento, mas é digno de nota que uma grande parte dos textos acadêmicos sobre megaeventos publicados em nosso país também não o faça. (TAVARES, 2011, p. 16)

Para Rolnik, urbanista, estudiosa das questões citadinas e políticas urbanas e relatora Internacional do Direito a Moradia Adequada do Conselho de Direitos Humanos da ONU (Organização das Nações Unidas), referindo-se aos megaeventos, diz que: "Esses eventos têm uma importância simbólica, têm um apelo nacionalista, mobilizam sentimentos que criam uma espécie de blindagem, como se para fazer isto acontecer valesse tudo". Uma determinada visão simbólica dos megaeventos também é compartilhada por Schimmel (1997).

Movimento, Porto Alegre, v. 18, n. 01, p. 69-99, jan/mar de 2012. 
Para Tavares (2011, p. 19)

[...] os megaeventos esportivos passaram a serem vistos como oportunidades de promoção para cidades e países em termos de legados econômicos, urbanísticos, sociais, culturais, ambientais e esportivos, entre outros, o que explica o envolvimento de governos nas candidaturas e organização de megaeventos esportivos. Este conjunto de fatos faz com que a Copa do Mundo de Futebol e os Jogos Olímpicos engendrem inversões financeiras, interesses públicos e privados, impactos sociais e audiência global não alcançáveis por nenhum outro evento conhecido.

No entanto, para Rolnik (2012, p. 3)

O megaevento é um estande de vendas das cidades e também das marcas dos patrocinadores. Esta é uma fórmula que pode constituir uma situação de exceção que cria uma privatização do próprio território. Ocorre uma espécie de suspensão da ordem pública vigente na cidade e uma introdução de outra ordem que domina e define as regras do espaço público. Copa do Mundo e Olimpiadas são eventos semelhantes, mas na Copa esse processo se dá de forma muito mais radical, pois no protocolo geral - tal como temos discutido a lei Geral da Copa - se estabelece um rol de novas regras que se sobrepõem às regras do país tal como um estado de exceção, como se estivéssemos em uma guerra, por exemplo. Para além disso, a FIFA estabelece miniEstados de exceção, já que ela cria leis específicas para cada cidade-sede, e, diferentemente da Lei Geral que está em discussão no Congresso Nacional, muitas delas nem passam pelas câmaras municipais e estaduais.

Claro que isso depende da negociação do país-sede. As negociações com a Alemanha e com a África do Sul foram totalmente diferentes. O Brasil, inclusive, diz que estudou as duas e que está tentando ser mais Alemanha que África do Sul. 
Produções da Sociologia do esporte nos Estados Unidos vão ter uma visão divergente de Tavares (2011), sobre as reais intenções dos governantes/políticos na promoção de megaeventos. Torna-se importante esclarecer que nestas os campeonatos nacionais ou ligas de baseball, soccer e football são considerados megaeventos. Euchner apud Schimmel (1997, p. 153) questiona se:

Esportes profissionais são bons para 'uma cidade'? Um novo complexo esportivo é um uso inteligente dos recursos 'da cidade'? E uma política de desenvolvimento do esporte serve aos 'interesses públicos'? Estas questões são, na melhor das hipóteses, conceitualmente falhas e politicamente inocentes: na pior das hipóteses, geram uma política pública regressiva. Um time esportivo pode servir como um veículo para simbolicamente construir um consenso na comunidade. No entanto, um símbolo tão forte de interesse comum pode também obstruir 'outros assuntos menos dramáticos que podem ser mais importante para a comunidade, como escolas, parques, moradias, e bibliotecas ${ }^{2}$.

Para exemplificar a distância que há entre o discurso político, a manipulação dos envolvidos e o "interesse público" a autora cita como exemplo a pesquisa de Euchner sobre o estádio de Baltimore:

Euchner demonstra em seu estudo de caso das políticas do estádio de Altimore, que as vizinhanças não tinham poder de influência sobre seus próprios destinos. Os beneficiários do desenvolvimento do estádio foram capazes de manipular o processo político de modo que o ponto de vista dos residentes fosse excluído. (SCHIMMEL, 1997, p. 118).

Schimmel tendo como referencia ainda as pesquisas de Euchner busca desvelar as intenções dos patrocinadores dos megaeventos nos EUA e o interesse dos políticos locais em promover eventos dessa natureza em sua cidade. Os extratos do artigo da autora são exemplares para a compreensão dessa questão:

\footnotetext{
${ }^{2}$ As traduções do inglês para o português foram realizadas por Luciana Moreira de Souza.
}

Movimento, Porto Alegre, v. 18, n. 01, p. 69-99, jan/mar de 2012. 
$\mathrm{Na}$ análise final, diz Euchner, a exaltação cívica liderada por um consenso elitista ganha a causa. A mídia local cobiça a associação com franquias de esportes profissionais por conta do status atrelado a estas relações. Banqueiros e empreendedores imobiliários promovem o esporte profissional pela oportunidade de investimento/acúmulo que eles representam. Políticos locais não resistem ao poder que as franquias de esporte profissionais oferecem. Nas palavras de Euchner, a analogia 'a cidade como um time' é útil aos políticos para 'dar definição e legitimidade à administração necessariamente tendenciosa da cidade' (SCHIMMEL, 1997, p. 172).

\section{Prosseguindo em sua análise Schimmel diz que:}

Oficiais eleitos localmente tem poder de governo muito limitado. Suas carreiras políticas são definidas de acordo como eles lidam com disputas de bairro ou resgatam instituições cívicas. Eles gastam suas energias tentando exercer uma influência modesta sobre um reduzido número de políticas na esperança de causar algum impacto positivo na economia política local. Talvez a maior ambição do 'repertório dos oficiais locais' sejam os projetos de construção de prédios de larga escala. (SCHIMMEL, 1997, p. 177).

[...] Políticos locais podem apontar a estádios, arranha-céus, ou centros de convenções e dizer, 'sem a minha ajuda, isto nunca teria acontecido'. 'O complexo de edifícios', de acordo com Euchner, 'é uma maneira de tornar a ineficiência de um político como um todo em um ganho político' (IDEM, p. 178)."

Schimmel (2006) analisa em outro artigo a relação entre interesses políticos e imagem das cidades promotoras de megaeventos, principalmente respondendo a questão de: como a reputação e projeção das cidades sede se dão?

A imagem de uma cidade compete com a imagem de outras cidades por reconhecimento, prestigio, e status. No termo mais simples, tendemos a pensar que uma cidade é um 'bom lugar' ou um 'lugar ruim'

Movimento, Porto Alegre, v. 18, n. 01, p. 69-99, jan/mar de 2012. 
e posicioná-la dentro do status da hierarquia global urbana. Até mesmo o nome de uma cidade pode evocar um sentimento, uma memória, ou imagem que pode variar de incrível a terrível. Quando acoplado a megaeventos esportivos, estas reputações são mais duradouras. Podemos pensar, por exemplo, em Sydney como uma cidade limpa e amigável, em Atlanta como uma cidade com tráfego congestionado, e Montreal como um grande ônus financeiro, e imagens ligadas aos ataques terroristas nos Estados Unidos em 2001 podem por longa data vir a mente quando alguém menciona a cidade de Salt Lake. (SCHIMMEL, 2006, p. 160)

O que nos leva a crer a partir das últimas citações de Schimel que o grande desejo de nossos políticos em trazer para o Brasil dois megaeventos com promessas de legados de difícil mensuração, deve ser também semelhante as intenções de políticos estadunidenses, ou seja ver nesta uma possibilidade de reconhecimento público e vantagens políticas de serem lembrados como os benfeitores e responsáveis pelos eventos.

O Secretário Nacional de Esporte Educacional do Ministério do Esporte em texto publicado no livro Legados dos Megaeventos diz que:

No contexto do Plano Nacional de Desenvolvimento do Esporte, a captação e a realização de megaeventos esportivos em cidades brasileiras, a partir sobretudo de uma ação determinada dos governos, adquirem maior centralidade num momento singular da história esportiva do nosso País. A realização com êxito dos Jogos Pan-Americanos e Parapan-Americanos 2007 torna inequívocos os diversos benefícios que podem ser alcançados e que devem ser revertidos para toda a sociedade na cidade sede, no Estado e no País. A infra-estrutura, o conhecimento, a tecnologia, entre outras áreas mobilizadas para a realização de um grande evento poderão potencialmente viabilizar o acesso de camadas significativas da população às políticas públicas em diversas áreas.

Movimento, Porto Alegre, v. 18, n. 01, p. 69-99, jan/mar de 2012. 
Sob essa ótica, do poder público, os legados de megaeventos esportivos são elementos indissociáveis da política pública e da função precípua do Estado, qual seja, de assegurar os direitos sociais fundamentais a todos os cidadãos, com qualidade, equidade e universalidade. Essa deve ser a referência básica que suporta toda a estratégia de promoção de megaeventos e, por consequência, de seus legados. (FILGUEIRAS, 2008, p. 67)

As produções acadêmicas sobre os jogos citados pelo secretário não confirmam sua análise otimista de sucesso dos mesmos, divergem radicalmente, inclusive nem mesmo as contas foram aprovadas pelo Tribunal de Contas da União. Até o momento equipamentos construídos para os jogos Pan Americanos do Rio não tem uso e nem manutenção, materiais se deterioram em almoxarifados, o estádio construído para as competições não poderá ser aproveitado na Copa do Mundo de 2014 etc.

A mais importante publicação sobre o tema afirma que:

[...]a maioria da população não teve acesso ao espetáculo. A presença nos Jogos Pan Americanos de 2007 era cara. Isso significa que as paredes em volta do estádio significava um limite entre o espetáculo colorido e moderno que atendia aos padrões internacionais e a cidade normal, com suas queixas de Terceiro Mundo. Esse muro teve que ser protegido por soldados altamente armados da Forca Nacional, detectores de metais e maquinas de raios$\mathrm{X}$. Esse equipamento de segurança é outro legado a cidade, mas é um legado que divide e, como tal, reproduz a desigualdade social ao invés de promover uma transformação social em direção a mais igualdade.

[...] Observadores internacionais comentaram sobre as construções de escudos para esconder as favelas. Black e Benzanson também observaram as violações sobre os seres humanos das comunidades marginalizadas que foram deslocados para dar espaço para a 'infra-estrutura relacionada as Olímpiadas e seus espaços' (CURI; KNIJNIK; MASCARENHAS, 2011, tradução minha).

Movimento, Porto Alegre, v. 18, n. 01, p. 69-99, jan/mar de 2012. 
Mesmo em um país com forte tradição de participação de capital privado em esporte e em construções de infraestrutura esportiva como os Estados Unidos, Schimmel demonstra que a maior parte do investimento dos recursos investidos em construções vem sendo público. Exemplo que contribui para uma preocupação ainda maior com os recursos públicos brasileiros que serão dispendidos nos próximos megaeventos que serão promovidos pelo Rio de Janeiro (2016) e pelo Brasil (2013 e 2014).

Para Schimmel (2006):

O esporte é associado ao discurso dominante de crescimento urbano e maneiras de regeneração que são tão poderosas quanto são problemáticas. Estas associações são ambas materiais e simbólicas e envolvem tanto capital fixo como capital de circulação. Adimensão material inclui a reconstrução de espaços urbanos e o uso de fundos públicos para o propósito de desenvolvimento de infraestruturas relacionadas ao esporte e mega projetos como estádios. A construção de estádios é necessária para reter importantes franquias de esportes profissionais existentes (em meio a ameaças de realocação de proprietários de franquias) e para obter expansão de franquias ou atrair a vinda de outras. Também é necessária para sediar mega eventos de esporte associados ao turismo, inclusive a partida do Super Bowl, da Liga de Futebol Nacional (NFL) [...]. O retorno público do investimento no desenvolvimento de importantes esportes é promovido para incluir inúmeros benefícios materiais, como o aumento de empregos e a criação de faturamento, para resolver problemas urbanos e, portanto beneficiar todos os residentes. Além disso, os benefícios simbólicos de sediar times profissionais ou megaeventos esportivos tendem a aumentar o status da cidade e a melhorar a 'qualidade de vida' da 'comunidade como um todo'. Quase duas décadas de pesquisas de ciência social negam as afirmações feitas por defensores do nível de crescimento local devido ao suposto benefício da 'cidade como um todo' no desenvolvimento de mega projetos esportivos. No entanto, o investimento

Movimento, Porto Alegre, v. 18, n. 01, p. 69-99, jan/mar de 2012. 
público em grandes construções de instalações esportivas continua em ritmo acelerado. Uma pesquisa nacional recente feita por Judd et al. (2003) revelou que dois terços das cidades centrais que responderam a pesquisa tinham construído ou estavam comprometidas a construir estádios esportivos. Expressos em dólares em 2003, o custo agregado de instalações esportivas gastos por franquias em esportes de alto nível como o futebol, beisebol, basquetebol, e hóquei foi de U\$23.8 bilhões. A quantia paga pelo setor público deste montante foi de aproximadamente U\$15.2 bilhões, o que representou 64 por cento do total [...]. (SCHIMEL, 2006, p. 163-164)

No Brasil o tão prometido legado dos megaeventos não tem se confirmado, outro exemplo disto na literatura é o apresentado por Reppold Filho (2008, p. 179) sobre os Jogos Olímpicos de Atlanta que:

[...] constituíram um modelo bem sucedido de planejamento e organização em vários aspectos, mas foram mal sucedidos em especial quanto aos direitos do cidadão. $\mathrm{O}$ evento não provocou o impacto esperado na regeneração urbana, especialmente nas áreas empobrecidas da cidade. $\mathrm{O}$ deslocamento da população não aconteceu da forma prevista.

Não bastasse a preocupação dos pesquisadores brasileiros sobre a fragilidade da concretização de legados materiais e imateriais positivos para os brasileiros a partir da promoção dos megaeventos Copa das Confederações e Copa do Mundo no Brasil, em recente artigo sobre futebol e crime organizado aparece os interesses escusos da promoção de eventos desta natureza em países emergentes. Sob o título de "Bird alerta que muito dinheiro e fiscalização frouxa dos países emergentes atraem o crime organizado para o futebol" encontra-se análises de Brigitta Maria Jacoba Slot:

Uma das autoras do primeiro estudo a avaliar mundialmente o envolvimento do crime com o futebol, do Banco Mundial, 'Brigitta garante que 
países emergentes como Brasil, Rússia e China estão na mira de quadrilhas internacionais que precisam legalizar o dinheiro obtido de forma ilegal.'

\section{[...]}

Segundo a consultora, o estudo dela, concluído em 2009 , identificou que os mecanismos de regulação e fiscalização do futebol são frágeis e insuficientes em praticamente todo o mundo. Além disso, falta transparência na condução dos negócios futebolísticos, como contratação de atletas e investimentos feitos por dirigentes de clubes e federações.

Concluímos que o futebol é vulnerável à lavagem de dinheiro e a outros crimes, como tráfico de pessoas e corrupção [...]. Para ela, o endividamento e a má governança dos clubes - inclusive os milionários times europeus, que também têm alto grau de endividamento -, a falta de fiscalização adequada por parte dos governos e a paixão que o esporte desperta são alguns dos fatores que contribuem para agravar o problema.

Como os demais palestrantes que participaram do seminário, a consultora do Bird classificou como injustificáveis e insustentáveis os altos salários pagos a jogadores e treinadores, além dos valores envolvidos nas transações entre clubes. 'O futebol é intocável na maioria das sociedades. Às vezes, as pessoas se perguntam quem controla quem? São os governos que impõem regras aos clubes ou é o contrário?'(RODRIGUES, 2011).

É tarefa da academia brasileira, considerada como parte importante da sociedade civil, contribuir com suas investigações e produções para que as ameaças não se tornem realidade e para que a sociedade brasileira não venha a ter mais prejuízos com a promoção destes eventos.

De certa maneira é o que se tenta fazer com a discussão sobre a vinculação de bebidas alcóolicas e violência em eventos esportivos. 


\section{Segurança em megaeventos e o álcool como vilão}

A questão da segurança em megaeventos tem sido muito pouco estudada na academia brasileira. Pode-se observar inclusive a ausência de publicações sobre o tema, como por exemplo, no livro Legados de Megaeventos, publicação do Ministério do Esporte (DACOSTA et al., 2008).

Dunning uma das maiores autoridades nos estudos da violência relacionada ao futebol ou como ele prefere denominar hooliganismo é muito enfático em afirmar que a atribuição da violência no futebol ao consumo de álcool por parte dos torcedores é um mito (informação verbal $)^{3}$. Ele utiliza o seguinte exemplo para refutar esta causa, diz que nem todos os hooligans bebem e nem todos os que bebem brigam em torno dos jogos de futebol.

Sem dúvida reduzir as raízes e causas da violência ao consumo de bebida alcóolica é um reducionismo inaceitável e uma explicação sociológica inconsistente. No entanto, compreendendo a problemática da violência em torno do futebol, principalmente aquelas manifestadas nas grandes cidades em dias de jogos de futebol profissional entre equipes arquirrivais como um problema complexo e multifatorial, pode-se sim incluir entre os fatores geradores de violência o uso abusivo de álcool pelos jovens espectadores de futebol.

Em pesquisa recente, Reis e Romera ${ }^{4}$ (2011) encontraram dados alarmantes sobre o uso abusivo de álcool entre jovens torcedores organizados de futebol. Enquanto aproximadamente 24\% dos jovens brasileiros (entre 18 e 24 anos) declararam fazerem uso de álcool em condições consideradas de risco (quando utilizado o AUDIT - Alcohol Use Disorders Identification Test - como instrumento de sondagem), as autoras encontram 36,9\% dos fiéis torcedores (entre 15 e 25 anos) nesse enquadramento de risco. Obviamente, que para se afirmar a relação entre violência e uso

\footnotetext{
${ }^{3}$ Palestra proferida no Simpósio sobre hooliganismo e Copa 2014. Campinas: Unicamp, maio 2011.

${ }^{4}$ REIS, H.H.B.; ROMERA, L.A. Lazer e futebol: o padrão de uso de álcool entre jovens torcedores do estado de São Paulo. Em avaliação em revista indexada. 2011.
} 
abusivo de álcool seria necessário outras investigações, como as que já foram realizadas na Espanha. Lá, a Policia Nacional, investigou os indivíduos detidos em situação de brigas e agressões e constatou que a maioria havia ingerido bebidas alcóolicas. No Brasil, ainda não há pesquisas neste sentido. No entanto, há uma atribuição ao maior número de brigas e mortes envolvendo torcedores de futebol às denominadas torcidas organizadas e constatar que uma parcela significativa deles tem um grande gosto pelo consumo abusivo de álcool nos possibilita ao mínimo refletir sobre os riscos de agressões e brigas sob o efeito do álcool.

[...] porcentagem de jovens que fazem uso regular de álcool leva a pensar que o consumo de álcool pode ser considerado um fenômeno crescente no Brasil principalmente em situação de lazer conforme resultados dos estudos de Pinsky e Bessa (2004), Cebrid (2005) ou por intermédio dos diversos levantamentos efetuados por seus pesquisadores aqui referenciados como Galduroz, Noto e Carlini, (1997); Galduroz, Noto, Fonseca e Carlini, (2005); e Galduroz, Noto, Nappo e Carlini, (2000), Galduróz, Noto, Fonseca e Carlini (2004), Galduroz e Caetano (2004).

Se por um lado o álcool tem um efeito socializador, por outro também estimula a violência e a impetuosidade (REIS, 2003 e 2006, ESPANHA, 1989, 1990), capazes de levar o jovem a assumir atitudes de risco, já que diminui o poder de avaliação, sendo um dos problemas de seu consumo em estádios de futebol ou mesmo antes do espetáculo em dias de jogos por aqueles que se dirigem aos estádios.

\section{$[\ldots]$}

A falsa sensação de estimulante que a bebida provoca nas primeiras doses, inibe a crítica e a capacidade de julgamento dos bebedores, assim como potencializa os sentimentos, dando a eles uma 
sensação de liberdade para expressar-se verbal e corporalmente, que muitas vezes leva-os a agirem de forma mais violenta, corajosa e perigosa. (REIS; ROMERA, 2011)

O Tratado do Conselho da Europa (ETS 120) de 1985, baseado em pesquisas europeias que vinculam a violência no futebol ao uso abusivo de álcool nos estádios europeus propôs aos estados membros a adoção de medidas preventivas, como a proibição da venda e consumo de bebidas alcóolicas nos estádios. Alguns países adotaram a medida e tiveram sucesso na redução ou extinção de cenas de violência no interior dos estádios. Na alínea f do ETS 120, aparece a proibição da introdução e venda de bebidas alcóolicas nos estádios. "Entre os países que mais se destacam na promoção de espetáculos futebolísticos estão a Espanha (firmou o convênio em 03/02/1986) e a Inglaterra (assinou o convênio em 19/11/1985), nações que aderiram a esta recomendação seja por meio de medidas administrativas ou legais." (REIS, ROMERA, 2011). No entanto, esta não foi uma medida isolada, foi conjunta com uma série de outras, como por exemplo: a instalação de um sistema de circuito fechado de vídeo câmeras, campanhas educativas e preventivas de intolerância a violência etc.

Tendo conhecimento disto e como resultado de pesquisa Reis (2000) propôs como medida necessária e preventiva a proibição da venda e consumo de bebidas alcóolicas nos estádios brasileiros. Uma primeira tentativa neste sentido foi muito mal interpretada e rechaçada no Seminário de Brasília em março de 2003; várias outras oportunidades de expor a sugestão foram propiciadas a partir de então sendo que em 2007 a mesma foi efetivamente encampada pelo CNPG (Conselho Nacional de Procuradores Gerais do Ministério Público dos estados e da União) (CNPG, 2008) que propôs a CBF (Confederação Brasileira de Futebol) um protocolo de intenções em 31 de agosto de 2007 com o objetivo de efetivar ações conjuntas para prevenir a violência nos estádios. Em 25 de abril de 2008 foi firmado entre estas um termo de adendo ao referido protocolo que restringiu o consumo e venda de bebidas alcóolicas no interior dos 
estádios. Na ocasião, o presidente da entidade, Ricardo Teixeira, disse que: "Com a proibição de venda de bebidas alcoólicas, pretendese reduzir substancialmente a violência nos estádios".

O debate em torno desta medida restritiva prosseguiu na esfera federal com minha participação em audiências públicas e palestras proferidas na capital federal, sendo que mais uma vez a sugestão de alguma maneira foi parcialmente acolhida no texto da Lei 12.299/ 2010, que incluiu na Lei 10.671/2003 o artigo 13-A que diz que:

Art. 13-A. São condições de acesso e permanência do torcedor no recinto esportivo, sem prejuízo de outras condições previstas em lei:

I - estar na posse de ingresso válido;

II - não portar objetos, bebidas ou substâncias proibidas ou suscetíveis de gerar ou possibilitar a prática de atos de violência; (BRASIL, 2010).

Em uma análise restrita do inciso II é implícita a proibição do porte de bebidas alcóolicas, no entanto, as Leis 10.671/2003 e 12.299/ 2010 nada dizem sobre restrição do consumo e da venda de bebidas alcóolicas no interior dos recintos esportivos. Apesar disso, entre os estudiosos do tema e operadores do direito é sabido da necessidade de regulamentação deste artigo expondo quais seriam as bebidas proibidas para que a intenção do legislador na propositura legislativa tivesse efeito.

As bebidas alcóolicas, de fato, são proibidas no estado de São Paulo através da Lei estadual n. 9.470 de 27 de dezembro de 1996, conforme pode ser conferido a seguir:

Artigo $5^{\circ}$ - Nos estádios de futebol e ginásios de esportes mencionados nos artigo $1^{\circ}$ ficam proibidas a venda, a distribuição ou utilização de:

I - bebidas alcoólicas;

II - fogos de artifício de qualquer natureza;

III - hastes ou suportes de bandeiras; e

Movimento, Porto Alegre, v. 18, n. 01, p. 69-99, jan/mar de 2012. 
IV - copos e garrafas de vidro e bebidas acondicionadas em lata.

Artigo $6^{\circ}$ - A proibição aludida no inciso I do artigo anterior estende - se, nos dias de jogos, a um raio de 200 metros de distância das entradas dos estádios de esporte. (SÃO PAULO, 1996)

Na cidade de São Paulo a proibição foi determinada através da Lei municipal no. 14.726 de 15 de maio de 2008, que traz em seu artigo $1^{\circ}$ :

Art. $1^{\circ}$ É vedado preparar, vender, expor à venda, oferecer, servir, transportar, trazer consigo, guardar, entregar a consumo ou fornecer, ainda que gratuitamente, bebidas alcoólicas nos estádios de futebol e conjuntos poliesportivos no Município de São Paulo no período de 2 horas antes e 1 hora depois dos eventos esportivos profissionais. (SÃO PAULO, 2008).

No estado de Pernambuco a Lei ordinária n. 13.748/2009 diz em seu artigo $1^{\circ}$. que:

Art. $1^{\circ}$ Fica proibido vender, expor à venda, oferecer, servir, transportar, trazer consigo, guardar, consumir, entregar a consumo ou fornecer, ainda que gratuitamente, bebidas alcoólicas no interior dos estádios de futebol e dos ginásios de esportes durante o período da realização de partidas e competições profissionais.

Os limites do legislativo no Brasil podem ser observados na transcrição a seguir da fala do deputado relator do PL, na Comissão Especial da Câmara ao portal, esta não é uma exceção no legislativo brasileiro, nota-se no trecho a seguir a falta de acuidade com a interpretação da legislação por parte do deputado, ademais da falta de conhecimento sobre a matéria em questão ${ }^{5}$.

\footnotetext{
${ }^{5} \mathrm{O}$ presidente da Câmara, Marco Maia, declarou ser favorável à venda de bebidas. "Impedir a venda de bebidas nos estádios não impede as pessoas de beberem antes ou depois do jogo, causando transtornos. O que precisamos é intensificar a fiscalização e endurecer as penas para quem comete alguma ilegalidade", analisou. (http://www2.camara.gov.br/ acesso em 08/3) Sobre a improbidade desta afirmação ver REIS (2006).
} 
Cândido afirmou que a venda de bebidas alcóolicas em estádios 'foi o item que mais se destacou durante o período de debates na Casa'. Ele disse ainda que a comercialização não aumentará a violência nos estádios porque o Brasil 'vive outro momento na comparação com dez, 12 anos atrás'. Ainda assim, o relator sugeriu que o Congresso terá de debater o assunto novamente para definir se a proibição determinada no Estatuto do Torcedor deve ser mantida. (SAVARESE, 2012, p.....)

Em nenhum de seus artigos, incisos, parágrafos o Estatuto do Torcedor (Lei no. 10.671/2003 alterado pela Lei no. 12.299/2010) determina a proibição da venda de bebidas alcóolicas em estádios. Como já exposto estas proibições são impostas por legislações estadual e municipal e em um número irrisório de estados e municípios brasileiros.

No entanto, com a Lei Geral da Copa em tramite no Congresso Nacional volta a pauta a polemica discussão sobre a proibição ou não do consumo de bebidas alcóolicas nos recintos esportivos, mais especificamente nos estádios de futebol em todo o território nacional. O que leva a necessidade de envidar esforços para esclarecimento sobre a pertinência ou não da liberação da venda de bebidas alcóolicas durante a Copa do Mundo de Futebol à realizar-se no Brasil em 2014.

\section{O NOVO TREM DA ALEGRIA: O QUE DIZ O RELATÓRIO ORIGINAL E O SUBSTITUTIVO DO PL 2.330/2011 ? ${ }^{6}$}

A proximidade do megaevento mais cobiçado do planeta tem trazido muito debate nos últimos meses sobre os possíveis legados que a Copa de 2014 deixaria ao Brasil. Os organizadores-defensores do evento desde o inicio asseguram que o país experimentará um

\footnotetext{
${ }^{6}$ Até o fechamento desse artigo o deputado havia apresentado duas versões do seu relatório a Comissão Especial que foi destinada a proferir parecer sobre o PL n. 2.330 de 2011.O presente artigo analisou a $1^{\mathrm{a}}$ versão apresentada em 6 de dezembro de 2011 e a $2^{\mathrm{a}}$ versão apresentada em 02/02/2012 com PL 2.686 de 2011 apensado. As versões seguintes mantiveram os trechos analisados nesse artigo, portanto os artigos e incisos aqui analisados foram para votação na Comissão Especial da Câmara e encaminhados ao plenário.
} 
avanço significativo em varias áreas, como a de transporte e infraestrutura urbana. No entanto, os críticos, tem dúvida sobre essas eventuais melhorias e ainda chamam a atenção para uma possível farra com o dinheiro público. Em meio aos debates, Executivo e Legislativo federais debatem os artigos e incisos contidos no projeto de lei que institui a Lei Geral da Copa (PL 2.330/2011). A forma como as discussões estão sendo conduzidas e algumas medidas contempladas na proposta de legislação suscitam preocupação, pois como em todos os projetos do Executivo foi criada uma Comissão Especial na Câmara dos Deputados, encarregada de apresentar parecer sobre a proposta, para isto foi indicado em 11/10/2011 o deputado Vicente Candido (PT/SP), da confiança do governo federal, para liderar (como relator) as discussões em torno da propositura legislativa e elaborar um relatório.

O mesmo apresentou um primeiro relatório (BRASIL, 2011b) no qual consta em seu preambulo a descrição do percurso realizado por ele para a elaboração do referido relatório. Neste consta que: "Esta Comissão Especial trabalhou de maneira participativa e flexível, mantendo aberta a possibilidade de sugestões para aperfeiçoamento da proposta." (BRASIL, 2011b, p. 5). Porém foi notada a ausência de participação da universidade e de seus pesquisadores. Além da ausência da academia, alijada das reflexões e críticas históricas sobre o tema, ao que consta o nobre deputado também não fez esforços para receber entidades que estão a frente do debate sobre a prevenção da violência em estádios desde ao menos 2007, como é o caso do Conselho Nacional de Procuradores Gerais (CNPG).

Desde o início dos trabalhos, alguns aspectos geraram muita polêmica. É o caso, por exemplo, do artigo que previa a liberação da venda de bebidas alcóolicas tanto durante o Mundial quanto depois dele, o que contrariaria (leis estaduais e o termo de adendo ao protocolo de intenções firmado entre CBF e CPNG em abril de 2008) mecanismo instituído depois de muitos debates e considerado uma conquista da sociedade. 
Pouco antes da abertura da sessão da comissão especial para avaliar a Lei Geral da Copa do Mundo de 2014, o Conselho Nacional de Procuradores Gerais (CNPG) divulgou uma nota para condenar a autorização proposta para venda de bebidas alcoólicas em estádios durante o torneio[...]

O órgão diz ainda que a decisão em favor da Fifa 'afrontaria o princípio da isonomia, revelando uma postura discriminatória em desfavor do torcedor brasileiro'. (SAVARESE, 2012).

Por conta das manifestações contrárias à medida, o relator da matéria, deputado Vicente Cândido (PT-SP), decidiu alterar seu relatório e apresentou um substitutivo que retirou o caráter permanente da autorização da venda de bebidas alcóolicas em estádios, entre outras modificações. Em outras palavras, se o torcedor, a mídia, o CNPG, a ABEAD (Associação Brasileira de Estudos do Álcool e Outras Drogas), alguns deputados de oposição e a universidade não tivessem alardeado novo trem da alegria havia passado com todos os comboios.

No substitutivo apresentado para votação, em 28 de fevereiro de 2012, permaneceu a vontade da maioria dos deputados e da FIFA, atendendo interesses puramente econômicos e agradando seu patrocinador oficial (uma imponente cervejaria internacional). Sendo assim, até o momento, os espectadores da Copa das Confederações FIFA 2013 e da Copa do Mundo FIFA 2014 poderão apreciar uma cervejinha no estádio de futebol, mas em copos descartáveis!

No relatório original e no substitutivo do deputado Vicente Cândido permaneceu a liberação da cervejinha nos estádios, desde que acondicionados em copos de plásticos em setores "populares", setores mais sofisticados poderão vender outros tipos de bebidas e em copos mais propícios ao estímulo do consumo e ao desfrute da bebida. Segundo as próprias palavras do relator no preâmbulo do substitutivo: 
[...] a venda e o consumo de bebidas, em especial as alcóolicas, nesses locais serão admitidos desde que o produto esteja acondicionado em copo de plástico, vedado o uso de qualquer outro tipo de embalagem. As restrições referentes ao tipo de embalagem não se aplicarão, no entanto, às áreas de hospitalidade. Ressalte-se que os locais oficiais de competição abrangem, nos termos do art. $2 .^{\circ}$, inciso XIV, do PL n. ${ }^{\circ} 2.330$, de 2011, não apenas os estádios, mas também os centros de treinamento, centros de mídia, centros de credenciamento, áreas de estacionamento, áreas para a transmissão de partidas, áreas oficialmente designadas para atividades de lazer destinadas aos fãs, localizados ou não nas cidades que irão sediar as competições, bem como qualquer local no qual o acesso seja restrito aos portadores de credenciais emitidas pela FIFA ou de ingressos. (BRASIL, 2011c, p. 19)

Já no texto substitutivo do projeto de lei a versão é:

Art. 29. Avenda e o consumo de bebidas, em especial as alcóolicas, nos Locais Oficiais de Competição, são admitidos desde que o produto esteja acondicionado em copos de plástico, vedado o uso de qualquer outro tipo de embalagem.

Parágrafo único. A vedação imposta no final do artigo não se aplica às áreas de hospitalidade. (BRASIL, 2011c, p. 41, grifo do autor)

Assim que foi divulgado o relatório original do deputado, a ABEAD manifestou-se por meio de matéria divulgada em seu site com o título "Atraso em nome da Copa a liberação: Álcool pode ser liberado nos estádios brasileiros já em março. A intenção é que a venda continue após o Mundial." Nesta Carlos Salgado, psiquiatra e conselheiro da Associação Brasileira de Estudos do Álcool e Outras Drogas (ABEAD), afirma que a medida é um retrocesso. Para ele:

Será um equívoco depois de décadas de luta contra a associação de esporte e bebida. Sem contar que é contra a vontade da população, pois $48 \%$ dos brasileiros não bebem. Dá para associar álcool e 
violência. O indivíduo responde impulsivamente depois de algumas doses e pode agir violentamente. (FOLHA UNIVERSAL, 2012)

Ainda segundo a matéria, a decisão da Comissão Especial da Câmara:

[...] é diferente da medida adotada pelos organizadores da Eurocopa deste ano, que será realizada na Ucrânia e na Polônia. A proibição à venda de bebidas está no estatuto de segurança adotado em 2006 pela Uefa - a entidade europeia de futebol que é responsável pela Eurocopa e por outros dos torneios mais lucrativos do mundo, como a Liga dos Campeões da Europa e a Liga Europa. (FOLHA UNIVERSAL, 2012)

As pesquisas sobre bebidas alcóolicas (ROMERA, 2008; REIS; ROMERA, 2011; MINAYO; DESLANDES, 1998; entre outras) apontam que se por um lado o álcool tem um efeito socializador, por outro também desinibe os indivíduos para a violência. A bebida diminui o poder de avaliação e leva a pessoa a assumir atitudes de risco.

Surpreendentemente enquanto produzia as últimas linhas deste artigo tomo ciência da matéria do Jornal do Brasil de 15 de março de 2012, na qual o relator diz que:

'Estamos entendendo que o governo não tem compromisso com esse artigo, não tem compromisso com a [Federação Internacional de Futebol] Fifa em relação à venda de bebidas nos estádios. Cabe a nós retirar do texto o dispositivo. Eu acho que fui induzido ao erro nesse item. Nesse caso, como é posição do governo e já havia várias rejeições, a base está achando melhor não encaminhar isso a voto', disse Vicente Cândido.

O relator declarou ainda que na sua avaliação houve mudança de posição do governo, pois a orientação que vinha recebendo durante a elaboração do seu parecer era no sentido de liberar a venda de bebidas

Movimento, Porto Alegre, v. 18, n. 01, p. 69-99, jan/mar de 2012. 
alcoólicas durante os dois eventos esportivos. 'Estamos entendendo que houve mudança de posição do governo, a orientação anterior foi com a concordância do governo'. (AGÊNCIA BRASIL, 2012).

O artigo 11 do substitutivo da Lei Geral da Copa assim como seu texto original, tem provocado desassossego também aos comerciantes instalados nas imediações dos estádios. Conforme a propositura caberá à FIFA ou a seu preposto "[...] divulgar suas marcas, distribuir, vender, dar publicidade ou realizar propaganda de produtos e serviços, bem como outras atividades promocionais ou de comércio de rua, nos Locais Oficiais de Competição, nas suas imediações e principais vias de acesso" (BRASIL, 2011c, p.9). O que a meu ver fere a autonomia dos proprietários de estabelecimentos comerciais de vender produtos da marca elegida por eles.

O texto original (BRASIL, 2011a) estabelecia no inciso XI do artigo 26 que seriam concedidos:

[...] sem qualquer restrição quanto à nacionalidade, raça ou credo, vistos de entrada para:

\section{$[\ldots]$}

XI - Espectadores que possuam ingressos ou confirmação de aquisição de ingressos válidos para qualquer Evento e todos os indivíduos que demonstrem seu envolvimento oficial com os Eventos, contanto que evidenciem de maneira razoável que sua entrada no país possui alguma relação com qualquer atividade relacionada aos Eventos". (BRASIL, 2011a, p.9) ${ }^{7}$.

Este artigo, da forma como apresentado, pode facilitar a entrada no país de hooligans, caso estes sejam possuidores de ingressos. Os procedimentos de concessão de visto obviamente devem ser o mais desburocratizado possível dentro de condições de segurança máxima, o que leva a crer que o procedimento habitual de concessão de visto

\footnotetext{
${ }^{7}$ Mantido pelo relator como inciso XI do artigo 19 no substitutivo ao PL2.330 de 2011, apresentado no relatório original do deputado Vicente Cândido.
} 
de entrada no país seria mais indicado, pois possibilitaria uma averiguação mais criteriosa sobre as reais intenções do visitante. Se um dos legados da Copa do Mundo, particularmente concedido pela Lei Geral da Copa for a criação de procedimentos mais modernos de concessão de visto, será computado um ganho, no entanto como dito deve ser estudado e testado para que a segurança seja garantida.

Os interesses políticos do legislador expressado no relatório original e no substitutivo da Lei Geral da Copa levado a segunda votação em 06 de março de $2012^{8}$ e aprovado na Comissão Especial da Câmara dos Deputados sobrepõe as reais necessidades de adequação da legislação brasileira ao exigido pela FIFA, expressada na carta endereçada a presidenta da República anexa a propositura legislativa original. Revivemos o trem da alegria, sendo que o legislador desta vez se sente autorizado a incluir ações de caridade com dinheiro público em benefício de ex-jogadores!

No capítulo IX das disposições permanentes o legislador propõe que:

Art. 38. Fica concedido aos jogadores, titulares ou reservas das seleções brasileiras campeãs das copas mundiais masculinas da FIFA nos anos de 1958, 1962 e 1970:

I - prêmio em dinheiro; e

II - auxílio especial mensal para jogadores sem recursos ou com recursos limitados.

Art. 39. O prêmio será pago, uma única vez, no valor fixo de cem mil reais ao jogador.

Art. 40. Na ocorrência de óbito do jogador, os sucessores previstos na lei civil, indicados em alvará judicial expedido a requerimento dos interessados, independentemente de inventário ou arrolamento,

\footnotetext{
${ }^{8}$ Após vários adiamentos para votação na Comissão Especial da Câmara criada para analisar a propositura legislativa, a votação ocorreu no dia 28 de fevereiro, porém houve um erro regimental na votação tornando-a nula e uma segunda rodada de votação ocorreu em 06 de março de 2012 com 09 votos contrários e 15 favoráveis. PPS, PSDB, PSC, PSB e Psol concentram parlamentares contrários à liberação de bebidas.
} 
poderão se habilitar para receber os valores proporcionais a sua cota-parte.

Art. 41. Compete ao Ministério do Esporte proceder ao pagamento do prêmio.

Art. 42. O prêmio de que trata esta lei não está sujeito ao pagamento de Imposto de Renda ou contribuição previdenciária.

Art. 43. O auxílio especial mensal será pago para completar a renda mensal do beneficiário até que seja atingido o valor máximo do salário de benefício do Regime Geral de Previdência Social.

Parágrafo único. Para fins do caput, considera-se renda mensal um doze avos do valor total de rendimentos tributáveis, sujeitos a tributação exclusiva ou definitiva, não tributáveis e isentos informados na respectiva Declaração de Ajuste Anual do Imposto de Renda da Pessoa Física.

Art. 44. O auxílio especial mensal também será pago à esposa ou companheira e aos filhos menores de vinte um anos ou inválidos do beneficiário falecido, desde que a invalidez seja anterior à data em que completaram vinte e um anos.

$\S 1^{\circ}$ Havendo mais de um beneficiário, o valor limite de auxílio per capita será o constante do art. 43 desta Lei, dividido pelo número de beneficiários, efetivos, ou apenas potenciais devido à renda, considerando-se a renda do núcleo familiar para cumprimento do limite de que trata o citado artigo.

$\S 2^{\circ}$ Não será revertida aos demais a parte do dependente cujo direito ao auxílio cessar.

Art. 45. Compete ao Instituto Nacional do Seguro Social - INSS administrar os requerimentos e os pagamentos do auxílio especial mensal. Art. 46. O pagamento do auxílio especial mensal retroagirá à data em que, atendidos os requisitos, tenha sido protocolado requerimento no INSS. 
Parágrafo único. Compete ao Ministério do Esporte informar ao INSS a relação de jogadores de que trata o art. 38 desta Lei.

Art. 46. O pagamento do auxílio especial mensal retroagirá à data em que, atendidos os requisitos, tenha sido protocolado requerimento no INSS.

Art. 47. O auxílio especial mensal sujeita-se à incidência de Imposto sobre a Renda, nos termos da legislação específica, mas não está sujeito ao pagamento de contribuição previdenciária.

Art. 48. As despesas decorrentes desta lei correrão à conta do Tesouro Nacional.

Parágrafo único. O custeio dos benefícios definidos no artigo 38 desta lei e das respectivas despesas constarão de programação orçamentária específica do Ministério do Esporte, no tocante ao prêmio, e do Ministério da Previdência Social, no tocante ao auxílio especial mensal. (BRASIL, 2011c, p. 4445)

O parecer do relator é ainda mais ousado propondo no artigo 55 que:

Art. 55. Os procedimentos previstos para a emissão de vistos de entrada estabelecidos nesta lei poderão ser também adotados para a organização da Jornada Mundial da Juventude - 2013, mediante prévia relação de visitantes estrangeiros, organizada pela Confederação Nacional dos Bispos do Brasil CNBB. (BRASIL, 2011c, p. 44)

Nota-se com o exposto que as propostas contidas no relatório original do relator, ora em apreço, que pretendiam modificar a Lei no. 12.299/2010 e a Lei no. 10.671/2003 não figuram no relatório substitutivo do deputado Vicente Cândido encaminhado para votação na Comissão Especial da Câmara dos Deputados em 06 de março de 2012. O que reafirma a necessidade permanente de total atenção da sociedade civil ao que ocorre no legislativo brasileiro. Espera-se que o plenário do Congresso Nacional seja mais rigoroso com os 
princípios da ética e da soberania nacional e não alterem leis anteriores que possam representar um retrocesso democrático, assim como não permitam que o novo trem da alegria saia do Congresso sob a chancela da Lei Geral da Copa.

O Estatuto do Torcedor (10.671/2003) é uma conquista importante da sociedade, como demonstrado no relato do presidente da suprema corte (Supremo Tribunal de Justiça) Celso Peluso. Para ele:

[...] o Estatuto do Torcedor é um conjunto ordenado de normas de caráter geral, com redação que atende à boa regra legislativa e estabelece preceitos de 'manifesta generalidade', que 'configuram bases amplas e diretrizes gerais para a disciplina do desporto nacional' em relação à defesa do consumidor.

O ministro ressaltou que, ao propor o texto do Estatuto, a União exerceu a competência prevista no inciso IX do artigo 24 da Constituição Federal. [...] [que] determina que a União, os estados e o Distrito Federal têm competência concorrente para legislar sobre educação, cultura, ensino e desporto.

[...] na medida em que se define o esporte como um direito do cidadão, este se torna um bem jurídico protegido no ordenamento jurídico em relação ao qual a autonomia das entidades desportivas é mero instrumento ou meio de concretização. (PELUSO, 2012 citado por KFOURI, 2012)

\section{CONCLUSÕES}

É papel da sociologia do esporte como campo de conhecimento relativamente autônomo avaliar a impertinência e as consequências da promoção da Copa do Mundo de 2014 no Brasil levando em consideração alguns dos riscos e prejuízos já apontados neste do ponto de vista econômico e do retrocesso legislativo analisado neste artigo. 
Sendo o Brasil (Comitê Organizador da Copa e as autoridades brasileiras) o responsável pela segurança durante a Copa do Mundo, não é aceitável que a FIFA nos "imponha" a liberação da venda de bebidas alcóolicas durante o evento entre outras. Medida que como exposta neste artigo contraria as lei estaduais e municipais em vigor além de colocar em risco o público nos eventos e ser uma afronta a soberania nacional.

De fato não há relatos históricos importantes sobre a incidência de eventos violentos no interior dos estádios em jogos de Copa do Mundo. Mas há abundantes provas de eventos de violência de proporções consideráveis nas cidades sedes de jogos de Copa do Mundo e em todas essas ficou evidente o alto consumo de cervejas pelos homens envolvidos. Há uma vasta literatura sobre futebol e hooliganismo a qual demonstra que como parte da cultura "macho" dos briguentos em torno do futebol está o habitus do consumo exaustivo e excessivo de álcool, principalmente a cerveja.

Pelo menos, desde a edição da Copa do Mundo na França a presença dos hooligans de diferentes países foi um fato, os tumultos e depredações em vias públicas ocorreram e a quantidade de agressões, lesões e detidos comprovam que é prudente que as autoridades brasileiras não cedam as pressões da FIFA.

Modificar leis, abrir exceções da natureza manifestada pelos nobres deputados apoiadores da FIFA expressas no relatório original e substitutivo da Lei Geral da Copa é minimamente desprezar o interesse da sociedade brasileira de preservar nossa soberania e perpetuar a ética na política. 


\section{Cup law, alcohol and the conception process of a legislation to violence \\ Abstract: This paper deals with the General Law of the World Cup which is being processed in Congress since September 2011, under the symbol PL 2330/ 2011 written by the executive branch. In such an analysis is made on the General Law of the World Cup and the construction of the legislation on prevention of violence and in sporting events, more detail on the controversial link between alcohol and violence. \\ Keywords: Legislation, violence, , Word Cup,}

Lei geral da copa, alcool y el proceso de
creacción de la legislación a relativa a la
violencia
Resumen: Este artículo se refiere a la Ley General
de la Copa del Mundo que se tramita en el Congreso
desde septiembre de 2011 , bajo el símbolo de PL 2330/
2011 escrito por el Poder Ejecutivo. En este se hace
análisis en la Ley General de la Copa del Mundo y la
elaboracción de la legislación sobre prevención de la
violencia en eventos deportivos, específicamente en
la relación entre el alcohol y la violencia.
Palabras clave: Legislación; violencia;; mundial de
fútbol.

Lei geral da copa, alcool y el proceso de creacción de la legislación a relativa a la violencia

Resumen: Este artículo se refiere a la Ley General de la Copa del Mundo que se tramita en el Congreso desde septiembre de 2011, bajo el símbolo de PL 2330/ 2011 escrito por el Poder Ejecutivo. En este se hace análisis en la Ley General de la Copa del Mundo y la elaboracción de la legislación sobre prevención de la violencia en eventos deportivos, específicamente en la relación entre el alcohol y la violencia.

fútbol.

\section{REFERÊNCIAS}

AGÊNCIA BRASIL. Lei da Copa não vai permitir vendas de bebidas nos estádios. Jornal do Brasil, Rio de Janeiro. Disponível em: http:/www.jb.com.br/pais/noticias/ 2012/03/14/lei-da-copa-nao-vai-permitir-venda-de-bebidas-nos-estadios/. Acesso em: 15 de mar. 2012.

BRASIL. Lei n. 10.671, de 15 de maio de 2003. Dispõe sobre o Estatuto de Defesa do Torcedor e dá outras providências. Disponível em:. http://presidencia.gov.br/ CCIVIL/LEIS/2003/L10.671.htm. Acesso em: 1 de mar. 2012.

BRASIL. Lei n. 12.299, de 27 de julho de 2010. Dispõe sobre medidas de prevenção e repressão aos fenômenos de violência por ocasião de competições esportivas; altera a Lei no 10.671, de 15 de maio de 2003; e dá outras providências. Disponível em: http://presidencia.gov.br/CCIVIL/LEIS/ 2010/L12.299.htm. Acesso em: 1 mar. 2012. 
BRASIL. Projeto de Lei n. 23.330 de setembro de 2011a. Dispõe sobre as medidas relativas à Copa das Confederações FIFA de 2013 e à Copa do Mundo FIFA de 2014, que serão realizadas no Brasil. Disponível em: http:// www.camara.gov.br/sileg/default.asp. Acesso em 08 mar. 2012.

BRASIL. Relatório do Projeto de Lei n. 23.330 de 2011b. Dispõe sobre as medidas relativas à Copa das Confederações FIFA de 2013 e à Copa do Mundo FIFA de 2014, que serão realizadas no Brasil. Disponível em: http:// www.camara.gov.br/sileg/default.asp. Acesso em: 03 fev. 2012.

BRASIL. Relatório do Projeto de Lei n. 23.330 de 2011 apensado o PL no. 2.686 de 2011C. Dispõe sobre as medidas relativas à Copa das Confederações FIFA de 2013 e à Copa do Mundo FIFA de 2014, que serão realizadas no Brasil. Disponível em: http://www.camara.gov.br/sileg/default.asp. Acesso em 15 fev. 2012.

CURI, M. ; KNIJNIK, J. ; MASCARENHAS, G. . The Pan American Games in Rio de Janeiro 2007: Consequences of a sport mega-event on a BRIC country. International Review for the Sociology of Sport, Otago, v. 46 no. 2, p. 140 156, 2011. doi: $10.1177 / 1012690210388461$

ESPAÑA. Ministerio de Educación y Cultura. Consejo Superior de Deportes. La prevención de la violencia en el deporte. Madrid, 1989. 4 v. (Documentação do Seminário Internacional).

ESPAÑA. Senado. Dictamen de la Comisión Especial de Investigación de la Violencia en los Espectáculos Deportivos con Especial Referencia al Fútbol. Madrid,, 1990.

FILGUEIRAS, J. C. M. Importância dos Legados de Megaeventos Esportivos para a Política Nacional do Esporte - Cidade, Cidadania e Direitos dos Cidadãos. In: DACOSTA, L. P. (Ed.). Legados de Megaeventos Esportivos. Brasília: Ministério do Esporte, 2008. p. 65-74.

FOLHA UNIVERSAL. Atraso em nome da Copa a liberação: Álcool pode ser liberado nos estádios brasileiros já em março. A intenção é que a venda continue após o Mundial. Disponível em <http://www.abead.com.br/midia/exibMidia/ ?midia=8684>. Acesso em: 12 de fev. 2012.

GALDURÓZ, J. C. F.; NOTO, A. R.; CARLINI, E. A. IV Levantamento sobre uso de drogas entre estudantes de $1^{\circ}$ e $2^{\circ}$ graus em 10 capitais brasileiras. São Paulo: CEBRID/Universidade Federal de São Paulo, Escola Paulista de Medicina, 1997.

GALDURÓZ, J. C. F.; NOTO, A. R.; NAPPO, S. A. e CARLINI, E. A. I Levantamento Domiciliar Nacional sobre Uso de Drogas Psicotrópicas. Parte A: Estudo Envolvendo as 24 Maiores Cidades do Estado de São Paulo - 1999. São Paulo: CEBRID/Universidade Federal de São Paulo,- Escola Paulista de Medicina, 2000. 
GALDURÓZ, J. C. F.; NOTO, A. R.; FONSECA, A. M.; CARLINI, E. A. V Levantamento Nacional sobre o Consumo de Drogas Psicotrópicas entre Estudantes do Ensino Fundamental e Médio da Rede Pública de Ensino nas 27 Capitais Brasileiras. Brasília: Secretaria Nacional Antidrogas; Centro Brasileiro de Informações sobre Drogas Psicotrópicas, 2005.

GALDURÓZ,J.C.F.; CAETANO, R. Epidemiologia do Uso de Álcool no Brasil. Revista Brasileira de Psiquiatria, v.26, supl. 1, p. 3-6, 2004,

MINAYO, M. C. S.; DESLANDES, S. F. A complexidade das relações entre drogas, álcool e violência. Caderno de Saúde Pública, Rio de Janeiro, v. 14, n. 1,p. 3542, jan. 1998.

PELUSO, C. Relato no Supremo Tribunal de Justiça. 2012 apud KFOURI, J. STF declara constitucionalidade do Estatuto de Defesa do Torcedor. Disponível em: <http://blogdojuca.uol.com.br/?s=.+STF+declara+constitucionalidade+ do+Estatuto+de+Defesa+do+Torcedor > Acesso em: 15 de mar. 2012.

PINSKY, I.; BESSA, M.A. (Orgs.). Adolescência e drogas. São Paulo: Contexto, 2004. p.16-31.

REPPOLD FILHO, A. R. A Regeneração Urbana e Direitos do Cidadão: o Caso dos Jogos Olímpicos de Atlanta 1996. In: DACOSTA, L. P. (Ed.). Legados de Megaeventos Esportivos. Brasília: Ministério do Esporte, 2008. p. 175-188.

REIS, H.H.B. Relatório de pesquisa: A violência nos estádios. São Paulo: Fundação de Amparo à Pesquisa do Estado de São Paulo, 2000.

REIS, H.H.B. Os espectadores de futebol e a problemática da violência relacionada à organização do espetáculo futebolístico. Revista Paulista de Educação Física, São Paulo, v.17, n.2, p.85-92, jul./dez.2003.

Futebol e violência. Campinas: Autores Associados/FAPESP, 2006.

RODRIGUES, A. Bird alerta que muito dinheiro e fiscalização frouxa dos países emergentes atraem o crime organizado para o futebol. Blog do Juca, São Paulo. Disponível em:< http://blogdojuca.uol.com.br/?s=Bird+alerta+que+muito +dinheiro+e+fiscaliza $\%$ C3\%A7\%C3\%A3o+frouxa+ dos+pa\%C3\%ADses+ emergentes+ atraem+o+crime+organizado+para+o+futebol >. Acesso em: 09 de dez. 2011.

ROLNIK, R. Entrevista. Disponível em:< http://ludopedio.com.br/rc/indez.php/ entrevistas/artigo/894.> Acesso em: 01 de mar. 2012.

ROMERA, L. A. Juventude, lazer e uso abusivo de álcool. $123 \mathrm{f}$. Tese (doutorado) - Curso de Educação Física, Faculdade de Educação Física, Unicamp, Campinas, 2008.

SÃO PAULO. Estado. Lei estadual n. 9.470 de 27 de dezembro de 1996. Dispõe sobre a manutenção de toda a lotação com lugares numerados nos estádios de futebol, ginásio de esporte e estabelecimentos congêneres. Disponível em:< 
http://www.al.sp.gov.br/portal/site/Internet/BuscaDdiLei?vgnextoid= 82ea0b9198067110VgnVCM100000590014acRCRD\&status $=$ P\&texto= bebidas\%20alcoolicas>. Acesso em mar. 2012.

SÃO PAULO. (Cidade). Lei municipal no. 14.726 de 15 de maio de 2008. Estabelece normas para repressão a comercialização e ao consumo de bebidas alcoólicas nos estádios de futebol e conjuntos poliesportivos no município de São Paulo, em eventos esportivos profissionais e dá outras providências. Disponível em: http://camaramunicipalsp.qaplaweb.com.br/iah/fulltext/leis/L14726.pdf. Acesso em: 10 mar. de 2012.

SAVARESE, M. Comissão da Câmara aprova texto básico da lei da Copa, mas deixa pendências para 4⿳亠丷. . UOL, Brasília. Disponível em: <http://esporte.uol.com.br/futebol/ copa-2014/ultimas-noticias/2012/02/28/comissao-da-camara-aprova-texto-basicoda-lei-da-copa-mas-deixa-pendencias-para-4.htm>. Acesso em: 29 de fev. 2012.

SCHIMMEL, K. S. The Edifice Complex: Reliance on New Sports Stadiums to Solve Urban Problems. Sporting Traditions, v. 14 n. 1, p. 160-174 nov. 1997.

Deep play: sports mega-events and urban social conditions in the USA. Sociological Review, Oxford: Blackwell, 2006. p. 146-155.

TAVARES, O. Megaeventos esportivos. Movimento, Porto Alegre, v. 17, n.3, p. 11-35, jul/set., 2011.

Recebido em: 15.03.2012

Aprovado em: 11.04.2012

Movimento, Porto Alegre, v. 18, n. 01, p. 69-99, jan/mar de 2012. 
